\title{
O Self Dialógico no Desenho Infantil
}

\author{
Dialogic Self in Children's Drawing
}

\author{
Nadja Maria Vieira da Silva ${ }^{a} \&$ Angelina Nunes de Vasconcelos ${ }^{*}, b$ \\ ${ }^{a}$ Universidade Federal de Alagoas, Maceió, Brasil \& ${ }^{b}$ Universidade Estadual de Campinas, São Paulo, Brasil
}

\begin{abstract}
Resumo
Aborda-se neste estudo a emergência de self dialógico com o objetivo de discutir o desenvolvimento infantil em situações de confecção de desenhos. Apresenta-se uma análise, fundamentada em pressupostos de Vigotski, Bakhtin e Hermans, de processos emergentes quando crianças entre um e três anos de idade produziram desenhos e falaram sobre eles. O método utilizado foi o estudo de casos com a análise de situações de interação videografadas. Esta análise foi apresentada como uma construção narrativa das pesquisadoras. Através desta narrativa, definiram-se, como resultados, dois aspectos relativos aos usos de linguagem que sustentam a emergência do self dialógico no desenho infantil: a regulação entre fala e ação e a produção de sentidos na experiência de alteridade.
\end{abstract}

Palavras-chave: Self dialógico, desenho infantil, fala.

\begin{abstract}
In this study we address the emergence of dialogical self in order to explain the process of children's development in activity of making drawings. Here, we present an analysis, based on assumptions of Vygotsky, Bakhtin and Hermans for processes emerging when children drew and talked about them. The method was cases study from analysis of interactions recorded in video. This analysis was presented as a narrative construction of the researcher where we highlighted, as result, two aspects relating to the uses of language that support the emergence of the dialogical self in the children's drawings: the regulation between speech and action and the reach of sense to the action and speech in the experience of otherness.

Keywords: Dialogical self, children's drawings, speech.
\end{abstract}

Para muitos pesquisadores, a análise da emergência de self tem sido considerada um desafio. Hermans (1996) reafirma a importância do estudo de self para a Psicologia, demonstrando como esta temática tem sido objeto da atenção nessa ciência ao longo do tempo. Redescobrindo uma diversidade de metáforas para o self como, por exemplo, o espelho, uma cebola com diferentes camadas, um ator em um palco, ele destaca a complexidade deste fenômeno e a necessidade de uma cautelosa investigação. Reiterando esta tendência para construção de metáforas voltadas para o funcionamento do self, este autor apresenta uma análise crítica da metáfora narrativa e do processamento de informação, as quais, em sua opinião, procuram retratar o funcionamento dialógico do self e propor modelos teóricos que orientem investigações empíricas.

Entretanto, no texto Voicing the Self: From Information Processing to Dialogical Interchange, Hermans (1996) declara a dificuldade de realização de pesquisas que tenham estas metáforas como base, afirmando que os estudos existentes não têm sido eficientes no que diz respeito à composição de análises que discutam o funcionamento dialógico e o aspecto multifacetado do self. Para ele, embora estas metáforas tenham grande potencial analítico, sua transposição para as pesquisas apresenta falhas, como a negligência das relações dialógicas e a composição de análises monológicas nas quais o selfé apresentado como "proprietário" de um discurso.

Nesta crítica, observa-se um reforço à concepção de self dialógico, com grande ênfase nos pressupostos de Bakhtin sobre o exercício da linguagem constituindo-se na experiência humana do tempo e do espaço (historicidade). Esta compreensão guia a proposição de Hermans (1996), onde o estudo de self pressupõe a captura da multiplicidade de posições, aspecto que traduz a sua dimensão dialógica.

\section{Self como Posicionamento}

Conceber self como posicionamento significa reconhecer seu funcionamento não restrito aos limites corporais ou a relações dicotômicas eu/não eu. Este reconhecimento opõe-se aquelas abordagens que se fundamentam no cartesianismo no que diz respeito à separação entre mente/corpo e interno/externo e ascende a necessidade da construção de parâmetros teóricos e metodológicos que capturem a natureza interdependente desses aspectos. 
A concepção de self como posicionamento apresentada por Hermans, resgata ideias desenvolvidas por W. James e Bakhtin. Como produto desse resgate, emerge uma caracterização onde self pressupõe autonomia relativa e posicionamento. Dito de outra forma, ao mesmo tempo em que o self reflete uma experiência de continuidade em que se reconhece como um mesmo ao longo do tempo, também vive uma experiência de descontinuidade refletida na alteridade; na medida e que se diferencia de seus interlocutores.

A discussão sobre a continuidade e descontinuidade incidente no estudo do self revela-se como principal orientação para identificá-lo enquanto posicionamento dialógico. Hermans (2001) sugere que W. James, um dos primeiros autores a discutir o aspecto multifacetado do self, "parece enfatizar a continuidade do self mais do que a descontinuidade" (Hermans, 2001, p. 246), embora, de acordo com o próprio Hermans, James tenha também considerado uma inerente descontinuidade. Acredita-se que a proposição de James de que a rivalidade entre as diferentes faces do self se resolva pela prevalência de um "eu" volitivo que suprime faces concorrentes, seja o fundamento maior para sua ênfase na continuidade. A sua afirmação de que "diferentes personagens podem concebivelmente no início da vida ser igualmente possíveis, mas para qualquer uma destas possibilidades ser de fato real, as outras devem ser mais ou menos suprimidas" (James citado por Hermans, 2001, p. 247), pode apoiar essa interpretação.

Por outro lado, Hermans (2001) observa que Bakhtin "que não foi psicólogo, nem inicialmente interessado na psicologia do self . . . enfatizou o princípio da descontinuidade mais do que o princípio da continuidade" (Hermans, 2001, p. 247). Bakhtin, diferente de James, não procurou "resolver" ou "anular" a descontinuidade do self, mas, através da noção de vozes e diálogo, afirmou que as diferentes vozes que compõem o self são autônomas e estão em interação constante, sem que nenhuma adquira o status de agente controlador das demais.

Emerge, portanto, desse debate entre continuidade e descontinuidade, uma concepção de self como lugar de organização e auto-regulação de posicionamentos, na medida em que:

O eu tem a possibilidade de se mover de uma posição espacial para outra de acordo com mudanças na situação e no tempo. O eu flutua entre posições diferentes ou até mesmo opostas e tem capacidade imaginativa para suportar cada posição com uma voz de modo que relações dialógicas entre elas se estabelecem. (Hermans, 2001, p. 248)

Observa-se que nessa caracterização conserva-se uma consonância profunda com declarações de Bakhtin e Volochinov (2009) que propõe o estudo do self a partir da investigação das interações sociais, reconhecendo sua constituição na fronteira, ou melhor, no espaço entre o eu e o outro, enquanto vozes funcionando como centros para iniciativas, possibilitando conflitos e desacordos em seus confrontos. Explorando a perspectiva dialógica de self de Bakhtin, Hermans (1996) destaca a espacialização no funcionamento do self dialógico, observando que "quando uma voz soa, ela está no falante e existe simultaneamente onde o som atingir. Um espaço é traçado entre esses dois lugares" (Hermans, 1996, p. 44). Por meio dessa observação, denota-se que uma posição é sempre localizada em concordância ou oposição com outras posições.

\section{Self Constituído na Linguagem}

Marková (2006), ao discutir as bases e pressupostos da perspectiva dialógica do self, afirma que Bakhtin foi um dos primeiros a declarar que vivemos no mundo das palavras dos outros, compreendendo que toda experiência do eu é orientada para o outro. Nesse sentido, a autora considera a dialogicidade como condição da mente humana, o que implica considerar a multiplicidade de vozes e posições que se estabelecem na alteridade e constituem o self.

Defende-se, portanto que, assumir esta concepção dialógica, implica compreender o desenvolvimento humano no âmbito das relações mediadas pela linguagem que o indivíduo estabelece com o contexto histórico e social que o cerca. Nessa perspectiva, o funcionamento de self é semiótico na medida em que o movimento entre diferentes posições é negociado, isto é, o trânsito entre diferentes posições é permeado por processos de significações e produção de sentidos.

Uma concepção de linguagem, que extrapola o funcionamento da oralidade, é defendida por Hermans na sua declaração de que "o conceito de self dialógico é concebido como um embodied ${ }^{1}$ self que encontra sua base na suposição de que o espaço não está apenas do lado de fora, como também no próprio self" (Hermans, 2001, p. 259). Além disso, o funcionamento do embodied self pressupõe questões, ainda pouco discutidas, acerca da natureza dos processos que vinculam diferentes dimensões ("interno; externo"). Defende-se aqui, que os processos que vinculam estas dimensões são distinções de natureza semiótica, mais especificamente, da linguagem.

Considerando as dificuldades para a investigação empírica do funcionamento do self apontadas por Hermans (1996) este trabalho apresenta uma análise do self dialógico a partir da discussão de casos. O contexto em que esta análise se desenvolve é a produção de desenhos por crianças entre um ano e seis meses e três anos de idade.

\section{A Emergência de Self Dialógico no Desenho Infantil}

Diferentes autores (Colaço, 2004; Greig, 2007; Silva, 1998; Vigotski, Luria, \& Leontiev, 1998) discutem diferentes perspectivas ao abordar o papel do desenho infantil, atividade lúdica frequente na maioria das cultu-

${ }^{1}$ Conserva-se aqui o termo em inglês devido à dificuldade de encontrar um termo equivalente no português, na tentativa de evitar possíveis prejuízos semânticos decorrentes de uma tradução parcial. 
ras, no desenvolvimento humano. Essas pesquisas têm se diversificado na forma de conceber a relação entre essa atividade e o funcionamento psicológico das crianças. Greig (2007), por exemplo, apresenta um detalhado estudo estatístico de traços característicos do desenho infantil. Como pressupostos básicos, esse pesquisador concebe o desenho como representações mentais. Todavia, refletir sobre a emergência de self no desenho infantil, na perspectiva da representação mental, é considerá-la dentro de metáforas que expandem a dicotomia entre mente e corpo, interno e externo.

Vigotski et al. (1998) discute outra possibilidade de se conceber o desenho infantil. Para ele o desenho, como brincadeira constitutiva do desenvolvimento infantil, revela-se como atividade de produção de significados e sentidos. Pontuando a relação entre o desenho e o desenvolvimento infantil, Vigotski et al. (1998) observa que no desenho especificamente, a criança opera com significados e símbolos ao invés dos objetos em si.

Acredita-se que esta característica do desenho infantil favorece a configuração de possibilidades específicas para emergência e organização do self. Com isto destaca-se que, para compreensão dessas especificidades, faz-se necessário uma abordagem que capture os processos implicados na relação entre o desenho e a fala da criança sobre o seu desenho. Uma abordagem com esse propósito afasta-se da ideia de representações mentais e elege o complexo funcionamento semiótico configurado pelos usos de linguagens, implicados na heterogeneidade e interdependência de organismo e ambiente. Por funcionamento semiótico, compreendem-se as operações com signos e símbolos por seres humanos, constituídos nos usos de linguagem ao ativarem relações entre indivíduos e coordenações intrapsíquica. Portanto, no processo de resgate de significados e de produção de sentidos emergente no contexto de fala entre as crianças que desenharam e um interlocutor, para quem elas descrevem seus desenhos, ou, dito de outra forma, na organização de elementos linguísticos pelas crianças sobre seus traços e riscos, acredita-se que, potencializam-se funções do self dialógico.

Com estas observações em mente, definiu-se como objetivo deste estudo, a análise de processos preliminares na organização do self dentro de uma abordagem dialógica em situações de produção de desenhos por crianças. Também foi interesse deste estudo destacar o papel central da linguagem nos processos de emergência de self e refletir sobre a noção de alteridade na fala das crianças sobre seus desenhos. Com esse propósito, encaminham-se as questões tecidas aqui com uma ênfase maior nas descontinuidades discutidas, principalmente, por Bakhtin e Volochinov (2009) a partir de sua análise da configuração espaçotemporal específica na negociação entre o indivíduo e as vozes sociais, aprofundadas por Hermans $(1996,2001)$. Essas referências são objeto de exploração nas análises com dados empíricos que serão apresentados em sessões posteriores deste estudo.

\section{Método}

Realizou-se um estudo de casos focalizando processos na emergência de self dialógico no desenho infantil. Nas análises, esses processos foram capturados considerando-se as mudanças reveladas nos eventos selecionados, onde se configurava a regulação entre fala e ação e outros aspectos implicados nessa configuração. Esta investigação centrou-se na análise da variação dos processos estudados na sua trajetória de ocorrência. Com este foco, pretendeu-se apresentar informações do fenômeno em desenvolvimento.

\section{Participantes}

Participaram deste estudo seis crianças com idades entre um ano e seis meses e três anos. As pesquisas que fazem uso de desenhos e falas infantis normalmente se referem a crianças entre três e cinco anos que frequentam a escola (Colaço, 2004; Silva, 1998). Entretanto, estas pesquisas comentam que as produções das crianças neste contexto já são muito marcadas pelas expectativas e exigências pedagógicas. Objetivando diversificar as informações nesse âmbito, analisaram-se aqui desenhos de crianças ainda não escolarizadas.

\section{Procedimentos para Coleta de Dados}

Os dados foram coletados na residência das crianças. As mães foram comunicadas sobre os objetivos do estudo e registraram o consentimento para a participação das crianças na pesquisa através do Termo de Consentimento Livre e Esclarecido (TCLE).

A situação para registro dos dados foi introduzida como uma brincadeira da qual uma das pesquisadoras também participou; criança e pesquisadora se envolveram na atividade de desenhar. Depois que as crianças desenharam, a pesquisadora as questionou sobre seus desenhos com o objetivo de estimular sua fala e a composição de narrativas sobre suas produções. Estes dados foram videografados.

\section{Procedimentos na Análise dos Dados}

Os vídeos foram assistidos e episódios de usos de linguagem foram selecionados e transcritos, preservando-se a dinâmica da alternação de turnos na interação entre as crianças e a pesquisadora (Sacks, Schegloff, \& Jefferson, 1974). Também foram transcritos aspectos não verbais relacionados com essa dinâmica. A análise da emergência do self dialógico foi realizada considerando-se aspectos verbais e não verbais, a partir dos quais se destacou a configuração de fenômenos que marcaram a negociação de posições na interação. Dessa forma, abordou-se a dimensão dialógica do self através da sua dinâmica espaço-temporal, pontuando-se a interdependência dos limites que definem a posição do eu e do outro.

A discussão desses dados foi constituída na análise narrativa das pesquisadoras. A atenção para a narrativa nesta investigação agrega a este estudo a caracterização de uma abordagem qualitativa de dados. A concepção de narrativa 
Silva, N. M. V. \& Vasconcelos, A. N. (2013). O Self Dialógico no Desenho Infantil.

desta pesquisa referencia-se nas declarações de Bruner (1991) e Flick (2007) acerca da construção narrativa da realidade e da forma de organização da experiência de pesquisadores relacionando-se com o contexto específico de uma investigação, respectivamente.

\section{Resultados e Discussões}

Os dados do presente estudo revelaram aspectos na configuração de self dialógico relacionados com as declarações de Bakhtin (1981; Bakhtin, \& Volochinov, 2009), Hermans (1996, 2001) e também de Vigotski (2001, 2005; Vigotski et al., 1998), onde a linguagem tem papel central. Apresentam-se aqui situações com dados empíricos onde se destacam três diferentes aspectos na abordagem do self dialógico, relacionado com este papel central da linguagem.

\section{Co-Regulação entre Fala e Ação e Emergência de Self Dialógico}

A análise dos dados aqui tratados ascendeu a discussão acerca da regulação entre fala e ação. Vigotski (2005) atentou para o momento dessa regulação marcando os primeiros indícios de uma atividade psicológica de natureza especificamente humana ao comparar comportamentos de crianças com de macacos antropoides. Nessa comparação ele assinalou que os macacos também fazem uso de ins- trumentos, símbolos e linguagem, entretanto de maneira qualitativamente distinta daquela que as crianças fazem. Uma das principais diferenças está na reorganização da atividade que as crianças expressam, quando a fala é também emergente nessa realização. $\mathrm{Na}$ análise de Vigotski, os macacos não revelaram uma composição entre fala e ação. Seus ruídos e vocalizações não têm função na execução de atividades práticas. Já para os seres humanos, fala e ação se complementam e se co-regularam. Em seu texto, A formação Social da Mente Vigotski (2005), declara que "Embora a inteligência prática e o uso de signos possam operar independentemente em crianças pequenas, a unidade dialética desses sistemas no adulto humano constitui a verdadeira essência no comportamento humano complexo" (Vigotski, 2005, p. 11).

Considerando os dados deste estudo, foi possível capturar variações na regulação entre fala e ação no contexto dos desenhos infantis. Foram analisadas as variações da relação entre a fala e os movimentos corporais e/ou deslocamentos da criança necessários para composição do desenho junto à pesquisadora. Os episódios abaixo podem servir como ilustração dessas variações.

\section{Episódio 1.}

O Episódio 1, foi selecionado a partir dos registros de uma criança de um ano e seis meses. Ela e a pesquisadora

Tabela 1

Iniciando a Interação Através dos Lápis

\begin{tabular}{|c|c|c|c|}
\hline $\mathrm{N}^{\mathrm{o}}$ & Part. & Transcrição Verbal & Processos não verbais \\
\hline 13 & $\mathrm{C} 1,6:$ & $(\mathrm{AÇ})$ & $\begin{array}{l}\text { Separa os lápis de cor que estão sobre a mesa. Pega alguns e os coloca } \\
\text { em frente à pesquisadora, depois empurra outros também em direção à } \\
\text { pesquisadora. }\end{array}$ \\
\hline 14 & P: & $\begin{array}{l}\text { É pra mim esse, é (\?) } \\
\qquad E(\backslash ?)\end{array}$ & $\begin{array}{l}\text { Olha para a criança, solta um dos dois lápis que estava segurando. Continua } \\
\text { segurando o outro. Arruma os lápis que a criança empurrou em sua direção } \\
\text { sobre a mesa. }\end{array}$ \\
\hline 15 & C1,6: & $(\mathrm{AÇ})$ & Continua empurrando os lápis em direção à pesquisadora. \\
\hline 16 & P: & Qual é que é seu (1?) & $\begin{array}{l}\text { Olha para a criança e para os lápis que ela havia juntado sobre a mesa na } \\
\text { sua frente. }\end{array}$ \\
\hline 17 & $\mathrm{C} 1,6:$ & $(\mathrm{AÇ})$ & $\begin{array}{l}\text { Pega os últimos lápis que restavam separados sobre a mesa e os coloca } \\
\text { junto à pesquisadora. }\end{array}$ \\
\hline 18 & P: & $(\mathrm{AÇ})$ & $\begin{array}{l}\text { Continua olhando para a criança e segurando um lápis vermelho na mão. } \\
\text { Todos os outros lápis estavam na mesa, no local onde foram colocados pela } \\
\text { criança, de modo que o lápis que estava em sua mão era o único que não } \\
\text { estava junto aos demais. }\end{array}$ \\
\hline 19 & $\mathrm{C} 1,6:$ & Dá outro & $\begin{array}{l}\text { Olha para o lápis vermelho que a pesquisadora segurava, pega o lápis da } \\
\text { mão dela, olha para a pesquisadora. }\end{array}$ \\
\hline 20 & P: & Quer esse (1?) & Olha para a criança, deixa a criança pegar o lápis de sua mão. \\
\hline 21 & $\mathrm{C} 1,6:$ & $(\mathrm{AÇ})$ & $\begin{array}{l}\text { Coloca o lápis vermelho junto aos demais, de modo que agora todos os } \\
\text { lápis estão sobre a mesa. }\end{array}$ \\
\hline
\end{tabular}

Nota: As legendas internas estão descritas na Figura 1, ao final do texto. 
estavam no quintal da casa da tia da criança desenhando e conversando. Também estavam presentes alguns familiares (tios e mãe). Neste registro da interação, a pesquisadora convidou a criança para desenhar entregando-lhe papel e lápis. A criança, então, começou a manipular os objetos.

Embora na transcrição (Tabela 1) não se mencione diretamente a produção gráfica (Figura 2) desta criança, correspondente ao Episódio 1, considerou-se relevante pontuar algumas informações sobre o momento em que a pesquisadora fez o convite para que ela e a criança desenhassem juntas, pois tendo disponibilizado o material necessário, papel e lápis de cor, em seguida a criança iniciou o manuseio do material. Observou-se então que desse manuseio derivaram informações que podem possibilitar a compreensão do desenvolvimento do self dialógico no contexto do desenho infantil, marcando o processo de negociação e caracterização de uma posição na interação, da descontinuidade entre vozes, capturada na trajetória da regulação entre fala e ação.

Destacou-se que, nesse episódio a criança predominantemente exercia a linguagem através de ações corporais, no início, com a ausência da fala. A pesquisadora tentou, todo tempo, compreender o que a criança queria comunicar, embora essa compreensão escapasse ou se estabelecesse de modo difuso. Naquela situação e em outras semelhantes, a pesquisadora regulou a sua própria fala às ações da criança.

Inicialmente trata-se aqui da regulação entre fala e ação marcando fronteira entre diferentes agentes na interação. Por exemplo, quando a criança pegou os lápis e os colocou sob a mesa em frente à pesquisadora (linha 13), a pesquisadora respondeu perguntando "É pra mim esse, é? É?" (linha 14). Do mesmo modo, quando a pesquisadora observou que a criança estava empurrando todos os lápis em sua direção, perguntou-lhe "Qual é que é seu?" (linha 16), procurando definir uma posição para criança na brincadeira.
A análise da regulação entre fala e ação nessas condições remonta características apresentadas em abordagens que discutem a organização de turnos conversacionais. A base para essa organização é a alternação na tomada de turno, o que promove a conversação, propriamente dita. Sacks et al. (1974) apresentaram a ideia de alocação de turnos com o objetivo de discutir parâmetros universais na análise da conversação. A possibilidade de parâmetros universais na conversação não é o interesse do presente estudo, todavia chama-se a atenção para uma ideia subjacente a alternação dos turnos conversacionais. Denomina-se de responsividade, o que mobiliza a alternação dos turnos. Além disso, destaca-se que é essa condição de responsividade que alimenta a regulação entre fala e ação. Quando marcando fronteiras entre diferentes agentes na interação, como por exemplo, a pesquisadora e a criança, supõe-se a falta de parâmetros claros que diferencie a fala da ação. Isto é, nesses cenários, fala e ação operam com um mesmo status: a tomada de turno. Outro fenômeno destacado na literatura que reflete a regulação entre fala e ação marcando diferentes agentes na interação, é o gesto de apontar no momento da aquisição de linguagem pelas crianças (Vigotski, 2005). Também não é interesse no presente aprofundar discussões acerca desse gesto, mas mencionar sua característica enquanto ação que regula fala, marcando diferentes agentes na interação ou mudança de turno, pois ao apontar a criança promove a fala do adulto que responde a este gesto.

Houve uma variação na regulação entre a fala da pesquisadora e as ações da criança no momento em que a criança disse "dá outro" (linha 19) e pegou o lápis que estava na mão da pesquisadora. Neste momento, a criança regula sua fala em função da ação da pesquisadora (esta segura um lápis vermelho, que se revelou ser do interesse da criança). Mas, além disso, a criança também regula sua fala e sua própria ação, na medida em que ao falar, olha

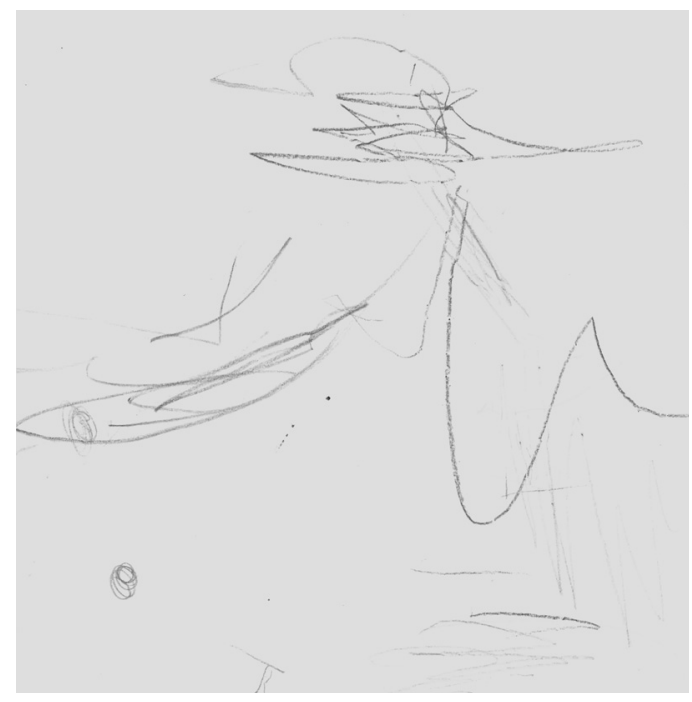

Figura 2. Desenho produzido pela criança de um ano e seis meses.

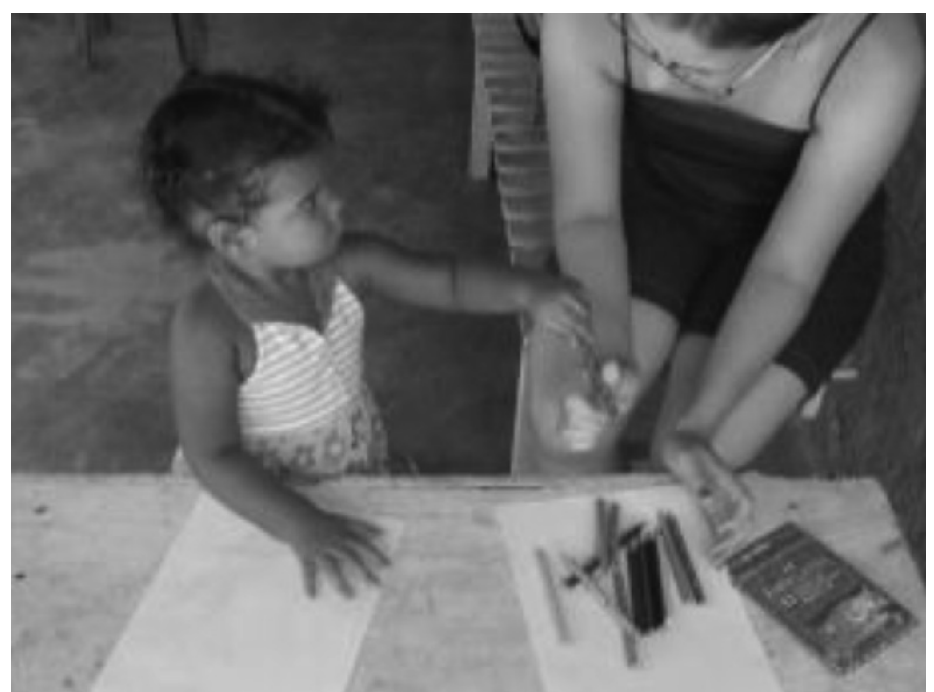

Figura 3. Momento em que a criança tem acesso ao lápis que estava na mão da pesquisadora e fala "dá outro". 
para a pesquisadora e apanha o lápis que estava em sua mão (a Figura 3 pode ajudar na visualização das ações da criança). Observou-se nesse momento que a criança, ao invés de pegar o lápis da mão da pesquisadora, como vinha fazendo, endereçou um pedido para poder ter acesso ao lápis, adiando o movimento com a mão. Desta forma ela exerce a possibilidade de planejamento e verificação de seu gesto e suas consequências.

Com a análise da variação na regulação entre fala e ação nesse episódio, chama-se atenção para uma diversificação na natureza dos processos semióticos que dão suporte às diferenciações de dimensões "interna" ou "externa" (ou anteriores e posteriores) no funcionamento do self. Essa diversificação pode ser explicada pela variação imanente na relação entre palavra e pensamento que foi abordada por Vigotski (2001), na sua defesa do sentido de unidade na análise de fenômenos psicológicos. A unidade que ele propôs foi palavra e pensamento, unidos pela significação "O significado da palavra é uma unidade indecomponível de ambos os processos e não podemos dizer que ele seja um fenômeno da linguagem ou do pensamento" (Vigotski, 2001, p. 398).

Na transcrição do Episódio 1 (Tabela 1), chama-se a atenção para a construção da significação nas linhas 13, $15,17,18$ e 21 . Nessas situações a significação se constituiu unicamente por meio de processos não verbais, como uma configuração possível do pensamento da criança (significação) relacionado com a fala (e os atos) da pesquisadora. Isto sugere uma forma de relação entre a palavra e a significação diferente daquela quando a criança fala.

Assim se considerou aqui a diversificação na natureza dos processos semióticos. Argumenta-se que essa diversificação reflete o movimento de posicionamento do self. Diferente do que sugere o posicionamento nas discussões acerca da continuidade temporal, pretende-se chamar a atenção para um sentido de posicionamento frente às significações emergentes implicadas em função da diversificação da natureza do material semiótico.

\section{Episódio 2.}

No Episódio 2 expandem-se essas observações, acrescentando-se a caracterização do desenho infantil como embodied self. Neste episódio (transcrição na Tabela 2) destaca-se a interação de uma criança de três anos em sua casa com seu irmão de sete anos e a pesquisadora. A pesquisadora e as crianças estavam em uma mesa no quintal desenhando e conversando; enquanto desenhavam, o irmão da criança falou que estava desenhando uma casa. A criança respondeu que desenharia uma casa também e após fazer alguns rabiscos, afirmou não saber desenhar uma casa, entregando seu desenho para a pesquisadora. Então a pesquisadora começou a fazer perguntas à criança sobre sua produção. A criança nomeou o que havia desenhado (Figura 4) ao mesmo tempo em que se movimentou subindo em uma mesa. Entretanto a pesquisadora ficou com dúvidas acerca do que foi enunciado pela criança, pois em sua fala não ficou claro se seu desenho foi nomeado como casa ou escada. A transcrição abaixo apresenta esse momento.

$\mathrm{Na}$ análise deste episódio reforçam-se fundamentos para o argumento de que o desenho infantil é lócus potencial para análise da emergência do self dialógico. Explica-se aqui a incidência da regulação entre fala $\mathrm{e}$ ação no desenho infantil como uma manifestação do funcionamento do embodied self. Ao subir na mesa (Figura 5) para completar sua fala "É é uma..." (Tabela 2, linha 2) na medida em que olhava para cima, apontando e se deslocando em direção a uma parede alta onde um sino de vento estava colocado, esforçando-se para alcançá-lo (Figura 6), unindo a fala "escada aqui" (linha 11); ou ainda, quando ficou na ponta dos pés e com os braços levantados, dando saltos enquanto falava "Pega, pega, pe" (linha 13), a criança estava constituindo o desenho, que ainda não existia nos traços que a pesquisadora tinha em mãos. As relações dialógicas emergentes naquele contexto impulsionaram aquela qualidade de responsividade.

O embodied self é uma caracterização revista por Hermans (2001) que diz respeito à possibilidade de movimento do self num espaço que não se situa exclusivamente fora do organismo. Ele ilustrou o embodiment do self com acontecimentos nos diálogos pré-verbais. O corpo do bebê é considerado o espaço do self, que, todavia, é concebido no sentimento de contraste e limite provocado pelo toque da mãe, por exemplo. Nesta caracterização é enfatizado o vínculo incondicional entre diferentes possibilidades de manifestações do self; entre as condições internas e externas; entre o antes e depois.

$\mathrm{O}$ argumento que se defende a partir dos dados da presente investigação é que a alta incidência da regulação entre a fala e a ação revela a intensidade da experiência do embodied self. O desenho em ação, que permeia toda a configuração do Episódio 2, é uma manifestação desse vínculo inviolável entre as arenas intrapsíquica e interpsíquica. A alta incidência dessa regulação revela a imprecisão dinâmica emergente no movimento do self no sentido de posicionar-se na interação.

$\mathrm{O}$ desenho em ação também chamou a atenção de Luria (citado por Vigotski, 2005) que observou que em estágios iniciais os desenhos são constituídos por gestos e, só posteriormente, assumem formas gráficas mais definidas. Para ilustrar essa observação, ele mencionou o caso de uma criança que, quando questionada sobre o desenho por ela produzido, declarou ter desenhado uma criança correndo referindo-se aos traços e pontos no papel que foram produzidos enquanto ela movimentava o lápis ao longo da folha, imitando o gesto de uma criança correndo.

Características do desenho infantil, como indefinição de traços e formas, apresentação por meio de movimentos da criança, apoiam a interpretação de que ele seja constituído, na medida em que o autor apresente-o para um interlocutor. Essa observação não é difícil de ser reconhecida. Frequentemente desenhos de crianças, visualizados, na perspectiva do adulto, como traços, rabiscos e pontos são 
Psicologia: Reflexão e Crítica, 26(2), 346-356.

Tabela 2

Construindo Desenho Sobre uma Escada

\begin{tabular}{|c|c|c|c|}
\hline $\mathrm{N}^{\mathrm{o}}$ & Part & Transcrição Verbal & Processos não verbais \\
\hline 1 & P: & E isso aqui é o que (1?) & Olhando para a criança e apontando para o desenho que ela fez. \\
\hline 2 & C3: & É (lher) é uma (...) & $\begin{array}{l}\text { Olhando para o papel e subindo na mesa que estava sendo } \\
\text { usada como apoio para desenhar. }\end{array}$ \\
\hline 3 & P: & É uma escada ou é uma casa (1?) & Olhando para a criança. \\
\hline 4 & N C3: & $\dot{E}$ (lher) para é (...।) & Ficando em pé sob a mesa. \\
\hline 5 & $\mathrm{I}:$ & Não suba (imp) & Olhando para a irmã. \\
\hline 6 & P: & Cuidado & Olhando para criança e segurando sua mão \\
\hline 7 & C3: & É pra subir assim & Ficando em pé sob a mesa. \\
\hline 8 & P: & $E \dot{e}(1 ?)$ & Olhando para a criança e segurando sua mão. \\
\hline 9 & C3: & $\begin{array}{l}\text { aaalcança (her) (...) o negócio lá } \\
\text { em cima }\end{array}$ & $\begin{array}{l}\text { Ainda em cima da mesa fica na ponta dos pés. Desce da mesa } \\
\text { e senta-se no chão. }\end{array}$ \\
\hline 19 & P: & Tem o que lá em cima $(\backslash ?)$ & Olhando para a criança. \\
\hline 11 & C3: & Escada aqui & $\begin{array}{l}\text { Olha para cima, aponta, se levanta e vai em direção a uma } \\
\text { parede alta onde um sino de vento estava pendurado. Fica na } \\
\text { ponta dos pés e levanta os braços na tentativa de alcançar o } \\
\text { objeto. }\end{array}$ \\
\hline 12 & P: & O que é isso que tem lá em cima (1?) & Olhando para o sino de vento pendurado na parede. \\
\hline 13 & C3: & $\begin{array}{l}\text { Pega, pega, (lher) } \\
\text { pe }\end{array}$ & $\begin{array}{l}\text { Ainda na ponta dos pés e com os braços levantados fica dando } \\
\text { saltos na tentativa de pegar o objeto. Pára e volta para sentar- } \\
\text { se no chão novamente. }\end{array}$ \\
\hline 14 & P: & $\begin{array}{l}\text { Há ( \!) Você sobe para pegar uma } \\
\text { coisa que ta lá em cima, né (I?) }\end{array}$ & Olhando para a criança. \\
\hline 15 & C3: & É, Assim ó & Olha para cima, começa a subir na mesa novamente. \\
\hline
\end{tabular}

Nota: As legendas internas estão descritas na Figura 1, ao final do texto.

acompanhados por uma complexa descrição pelas crianças autoras, quando solicitadas. Essas situações suportam a interpretação de que o desenho é constituído na linguagem (fala e/ou gestos) e que por sua vez, não pode prescindir da sua propriedade, o endereçamento. Isto é, a linguagem funciona como endereçamento. Ela transita entre fronteiras do eu e do não-eu.

No momento em que a criança fala e age, ela marca uma posição e reorganiza o ambiente. Dessa forma o self como expressão ativa e volitiva é constituído para além das fronteiras do organismo estritamente biológico. No momento em que a criança do Episódio 2 falou sobre esta escada e encenou seu uso, ela utilizou conceitos culturalmente constituídos, ao mesmo tempo em que os apropriou em situações específicas, atualizando usos desses conceitos. Reconhece-se, então, o movimento do self emergindo nas apropriações ou atualização de conceitos e condições de uso da linguagem em situações específicas, marcando posições diferenciadas frente às interlocuções.

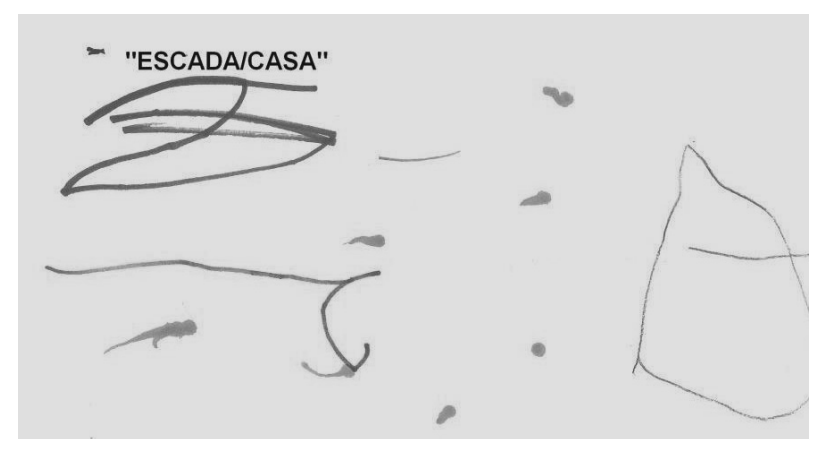

Figura 4. Desenho produzido pela criança de 3 anos, nomeado como casa e escada. 


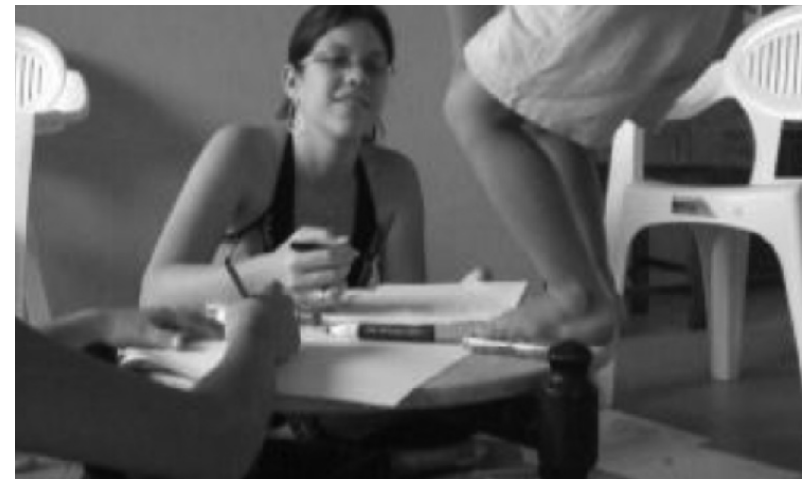

Figura 5. Criança sobe na mesa enquanto fala sobre a escada.

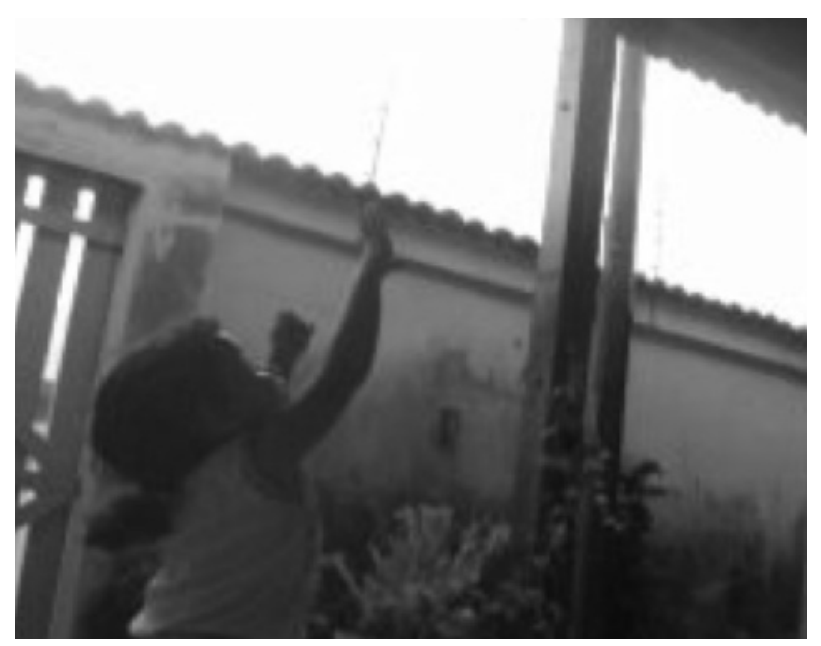

Figura 6. Criança tentando alcançar um sino de vento sinalizando a função de uma escada.

Produção de Sentidos: A Regulação da Fala e Ação na Experiência da Alteridade. Atualizações de conceitos e significados historicamente construídos e culturalmente consolidados a partir do uso por pessoas em situações interativas específicas, não podem prescindir do reconhecimento e compreensão desses usos, uma vez que na ausência desse reconhecimento, a comunicação propriamente dita, não teria lugar. Os processos que asseguram o reconhecimento dessas atualizações, isto é, desses usos pessoais da linguagem, tem sido denominado na literatura como produção de sentidos.

Bakhtin e Volochinov (2009) observaram que a linguagem tem uma dimensão mais estável, marcada pelos significados que se estabelecem de maneira mais ou menos estável na cultura, mantendo relação com a dimensão da produção de sentidos onde os significados adquirem variabilidade. Estes sentidos mantêm relação com a dimensão do significado, mas marcam usos criativos e únicos das palavras e gestos das pessoas em determinadas condições e contextos específicos que não podem ser repetidos.

No episódio da escada, por exemplo, a criança ficou na ponta dos pés e se esticou na direção de um sino de vento pendurado em uma das paredes do ambiente, na tentativa de ilustrar a função de uma escada que parecia estar no papel e não tinha sido reconhecida pela pesquisadora (Figura 6). A simples presença do sino de vento ou a fala isoladamente não seria suficiente para promover aquela resposta da pesquisadora, quando relacionou os gestos e fala da criança à escada. No contexto do desenho infantil, a produção de sentidos apoiou-se na regulação entre fala e ação para compartilhar experiências sobre os traços e rabiscos.

A caracterização da produção de sentidos como operações de uso de linguagem que se efetivam como atualizações circunstanciais de significados culturais não pode prescindir de outro aspecto na análise da emergência do self dialógico: a função da alteridade. A função da alteridade pressupõe posicionamentos na produção de sentido. A esse respeito, Brait (2005) comenta que é na alteridade que ocorre a experiência de descontinuidade entre eu/não-eu, na qual o self se realiza não em uma perspectiva de síntese, mas em seu caráter dialógico constituído por diferentes vozes que possibilitam a construção de um sujeito histórico e ideológico que emerge no evento único de sua realização, em um tempo e espaço específicos.

O Episódio 3, com registros de uma criança de dois anos, ilustra uma análise do complexo funcionamento da produção de sentidos Pressupondo-se a experiência da alteridade e o posicionamento de agentes frente a cultura ontologicamente significada. Neste episódio, a criança estava no seu quarto desenhando e conversando com a pesquisadora. Durante toda a atividade, as cores dos lápis apareceram como tema central para a criança. Em determinado momento instalou-se um jogo entre criança e pesquisadora. Este jogo consistia em: A pesquisadora mostrava um giz de cera para a criança, dizia a primeira letra da cor do giz e a criança respondia nomeando a cor.

\section{Episódio 3.}

$\mathrm{Na}$ análise deste episódio transcrito na Tabela 3 , também foram capturados movimentos de posicionamentos da criança e da pesquisadora na interação. Na linha 19 desta tabela, a pesquisadora fala "esse é o", esperando que a criança nomeasse a cor do giz de cera que estava utilizando, como vinha fazendo anteriormente. Entretanto a pesquisadora não compreende o que a criança fala (na linha 20, o símbolo (...) marca a presença de fala não compreendida). $\mathrm{Na}$ linha 21 a pesquisadora tenta compreender o que foi dito pela criança perguntando "O branco?". Entretanto, a nomeação "branco" pareceu não ser reconhecida naquele momento da interação provocando uma quebra na comunicação. $\mathrm{O}$ indicativo para essa interpretação foi o turno seguinte da criança, que falou "eu vou escrever esse" (linha 22). Esta foi uma fala aparentemente desconectada da fala da pesquisadora. Todavia ao falar "eu vou escrever esse", a criança apanhou outro giz de cera vermelho (linha 22) e pintou com ele. Note-se que no turno anterior da pesquisadora, esta havia deixado um giz de cera vermelho no chão (linha 21). 
Tabela 3

Falando Sobre as Cores dos Giz de Cera

\begin{tabular}{|c|c|c|c|}
\hline $\mathrm{N}^{\mathrm{o}}$ & Part & Transcrição Verbal & Processos não verbais \\
\hline 18 & $\mathrm{C} 2 \mathrm{:}$ & $(\mathrm{AÇ})$ & Criança desenhando com giz de cera verde. \\
\hline 19 & P: & E esse éo $(\ldots)$ & Olhando para a criança. \\
\hline 20 & $\mathrm{C} 2:$ & $(\ldots)$ & Coloca o giz de cera verde no chão. \\
\hline 21 & P: & O branco $(\backslash ?)$ & Coloca o giz de cera vermelho que tinha na mão no chão. \\
\hline 22 & $\mathrm{C} 2:$ & Eu vou escrever esse & Pega outro giz de cera vermelho no chão e começa a pintar \\
\hline 23 & P: & Vai escrever o quê (1?) & \\
\hline 24 & $\mathrm{C} 2:$ & Esse & Riscando com o giz de cera vermelho. \\
\hline 25 & P: & Esse (१?) & \\
\hline 26 & $\mathrm{C} 2:$ & $(\mathrm{AÇ})$ & Coloca o giz de cera vermelho no chão e pega um azul. \\
\hline 27 & $\mathrm{P}:$ & E esse é o a $(\ldots 1)$ & \\
\hline 28 & $\mathrm{C} 2:$ & $O A B C(\backslash !)$ & Pinta com o giz de cera azul. \\
\hline 29 & P: & O A B C(\!?) É o azul! (\!) & Rindo. \\
\hline 30 & $\mathrm{C} 2:$ & É o azul (\!) & Solta o giz de cera azul e pega outro para desenhar. \\
\hline 31 & P: & É o azul (\!) & \\
\hline
\end{tabular}

Nota: As legendas internas estão descritas na Figura 1, ao final do texto.

Ao pegar um giz de cera vermelho, semelhante aquele deixado pela pesquisadora, pode-se pensar que a compreensão da criança foi de que a pesquisadora não conhecia a cor verde, visto que, quando a criança tinha esta cor de lápis na mão, e pronunciou algo, que não fora compreendido pela pesquisadora, esta indagou-lhe se aquele era um lápis "branco" (linha 21). Essa é uma interpretação possível, todavia, na produção de sentidos, com usos situados e circunscritos ao evento, chama-se a atenção para o caráter de potencial indeterminação $a$ priori.

Não é interesse desta análise, defender explicações que pressuponha uma dimensão exclusivamente interna de funcionamento de self, aliás, esta é uma das contestações principais deste estudo. Todavia, acredita-se ser oportuno refletir aqui algumas considerações tecidas por Hermans (2001) acerca de um modelo possível para o movimento de posicionamentos do self. Na apresentação desse modelo o autor sugere a existência de um vínculo entre as diferentes arenas no processo de negociação das posições. Através deste modelo, ele observa que o self se expressa no entrelaçamento de posições internas e externas como uma atitude volitiva.

Na configuração dos dados do presente estudo, situouse a produção de sentidos no processo da atualização das vozes que se configurou como uso criativo e circunstancial de significações historicamente sedimentadas nas interações sociais (Bakhtin \& Volochinov, 2009). A dimensão de vozes sociais revela-se como uma arena mais estável no uso de conceitos historicamente concebidos e partilhados entre os usuários de uma ou mais línguas. Assim, na produção de sentidos revela-se o entrelaçamento entre diferentes arenas para posicionamento do self.

Nas análises deste estudo, chama-se a atenção para a reorganização da produção de sentidos quando se regula, fala e ação. Ainda na análise do Episódio 3, captura-se mais uma das configurações na interação entre a pesquisadora e a criança que podem ilustrar o vínculo entre as diferentes arenas (uma mais estável e uma circunstancial) através do qual o self se expressa em movimento para posicionar-se na interação. Na Tabela 3, linha 27, a pesquisadora fala: "esse é o aa..." referindo-se ao lápis azul que a criança está utilizando (linha 26). Então a criança responde: “ $O$ $A B C$ !" (linha 28).

No episódio em questão, “ $O A B C$ " emergiu como possibilidade devido a experiências culturais da criança. Numa situação de uso de linguagem, ela reorganizou (atualizou) possibilidades relacionadas com a indicação da letra "a" circunscrita ao evento. As possibilidades de reorganização ou atualização refletem a dimensão ontológica da experiência cultural. Ao falar " $O A B C$ " a criança marca uma posição no diálogo e distingue-se na interação, promovendo a descontinuidade na negociação de significados, ao contrariar expectativas da pesquisadora, sobre a palavra "azul". Todavia, quando a criança fala: " $O A B C$ ", ela compartilha 
uma experiência cultural, mesmo que a pesquisadora não estivesse esperando esta resposta (pois ela esperava que a criança completasse dizendo azul, cor do giz em questão). Com " $O A B C$ " como resposta, tanto pesquisadora quanto criança converge para um sentido na interação.

Note-se, no entanto, que foram expectativas da pesquisadora que marcaram a diferenciação (posicionamento) da criança na situação. Dessa forma pontua-se a relação entre a produção de sentidos e a experiência da alteridade e ratifica-se a função do embodied self. Isto é, o alcance dos sentidos para os usos circunstanciais de significados historicamente estabilizados (embora sejam estes também passíveis de revisões ao longo da história do uso) pressupõe que, em última instância, as diferentes arenas (intra e interpsíquica) sejam envolvidas por uma arena ainda mais ampla (da História do significado em questão). Dessa forma-se se reconhece a inviabilidade de se conceber dimensões internas e externas como dicotomias mutuamente exclusivas. No sentido do Hermans (2001), essa instância sempre mais ampla na movimentação do self para um posicionamento na interação, que pressupõe a existência de um embodiement self, se revela na dinâmica entre uma fronteira e o que ela demarca para o posicionamento do self. Ou melhor, a fronteira não separa, mas vincula diferentes arenas (interna, externa, antes, depois).

$\mathrm{Na}$ interação registrada no Episódio 3, ao manifestarem-se de diferentes maneiras em relação à letra "a", compondo o "ABC", para a criança e sinalizando a palavra "azul" pela pesquisadora, elas posicionaram-se refletindo diferentes trajetórias no diálogo. Essas descontinuidades são operadoras da produção de sentidos; embora compartilhem significados consolidados na cultura, as pessoas os experimentam em diferentes trajetórias ontológicas. Ao falar "esse é o aa..." a pesquisadora reorganiza o material semiótico em funcionamento que dispõe, movimentando-se no sentido de manter uma correspondências entre as diferentes arenas. O conceito "azul" como expectativa, a situa na arena de uma significação cultural estável. Entretanto, de forma volitiva e criativa, o movimento da criança para essa correspondência emergiu com a sua fala " $O A B C$ ". Embora tanto a criança, quanto a pesquisadora sinalizem seus sentidos para " $a a . .$. " resgatando significados estáveis (ABC e Azul, respectivamente), marca-se diferentes trajetórias. Na interação, o sentido é alcançado quando, pressupõe-se que os diferentes atores da interação se inserem temporariamente numa mesma arena. Todavia é importante observar que até nas últimas linhas deste episódio de interação, quando a criança e a pesquisadora repetem a mesma palavra: "azul" (linhas 30 e 31), estes usos estão marcados por posições diferenciadas que se revelam inclusive nas entonações utilizadas.

\section{Considerações Finais}

O objetivo central deste estudo foi apresentar uma análise da emergência do self dialógico que o destacasse constituído linguagem. Nesse percurso defendeu-se o argumento de que o desenho infantil potencializa a emergência de processos que refletem essa constituição. A partir de um ambiente empírico, que teve o desenho infantil acompanhado por narrativas das crianças autoras dessas produções, observou-se a incidência da regulação entre fala e ação como construções narrativas típicas.

É possível dizer que o desenho tornou-se vivo na fala acompanhada por ações tão características dessas situações. Nesta investigação interpretou-se essa incidência como qualidade do movimento para o posicionamento do self na interação ao transitar entre diferentes arenas semióticas (espaciais - internas e externas e temporais). Destacaram-se nessas situaçoes estratégias ontológicas típicas daquelas crianças, ao buscar estabelecer fronteiras entre ela mesma e o desenho.

A regulação entre ação e fala anunciou o desenho como extensão do self. No destaque para o vínculo entre diferentes arenas semióticas revelou-se a essencialidade da linguagem na constituição do self. Isto porque, como foi ilustrado nos diferentes episódios, é um funcionamento semiótico (de significados e sentidos) que permeia as possibilidades de diferentes posições do self interação. Nos dados do presente, o movimento para variação das posições foi abordado principalmente por um processo de diferenciação na interação, situando o funcionamento do self na alteridade. Dessa forma, com ilustrações empíricas, conferiu-se que o self dialógico se realiza na provocação da descontinuidade entre o eu e o não-eu; como posicionamentos no diálogo a partir dos usos da linguagem; na produção de sentidos, atualizando significados consolidados na cultura relacionados á objetos e conceitos.

A expectativa é que as informações que resultaram dessa investigação possam servir como um incentivo para a revisão de fundamentos acerca da continuidade do self. Acredita-se que, subjacente à continuidade, está, em maior relevância, a descontinuidade revelada no processo de atualização de significados e produção de sentidos. Com esta observação fragiliza-se o sentido do mesmo self ao longo do tempo. Há mais plausibilidade na explicação acerca da descontinuidade que o self dialógico experimenta nesse movimento para posicionar-se e distinguir-se na alteridade. Nessa explicação, a concepção de embodied self possibilita compreender que se inclui nas atualizações todo o percurso até então percorrido na historicidade do self.

Outra expectativa que também derivada dessa investigação é a revisão de abordagens mais tradicionais que analisam a relação entre o desenho e o desenvolvimento infantil. Acredita-se que, se explorado, o enfoque na incidência da regulação entre fala e ação e a caraterização do desenho como uma extensão do self dialógico, poderá revelar a inconsistência de perspectivas que tratam o desenho infantil como atividade que projeta o psiquismo, como representação mental, atribuindo-lhe uma natureza exclusivamente interna. 


\begin{tabular}{lll} 
C1,6: Criança de um ano e seis meses. & (\!) Enunciado exclamativo & $\mathrm{N}^{\mathrm{o}}$ : Número correspondente ao turno de fala. \\
C2: Criança de dois anos. & $(\backslash /)$ Pausa breve & (...) Fala incompreensível \\
C3: Criança de três anos. & $(\backslash / /)$ Pausa longa & (Rep) Repetição \\
I: Irmão da criança de 3 anos. & $($ (imp) Imperativo & (...) Fala incompleta. \\
P: Pesquisadora & $($ (her) Hesitação/repetição & (AÇ) Turno de ação. \\
Part.: Participante & $((:)$ Alongamento vocálico & (।?) Enunciado interrogativo \\
\hline
\end{tabular}

Figura 1. Legenda interna referente a todas as transcrições presentes neste texto.

\section{Referências}

Bakhtin, M. (1981). Problemas da poética de Dostoiévski. Rio de Janeiro, RJ: Forense Universitária.

Bakhtin, M., \& Volochinov, V. N. (2009). Marxismo e filosofia da linguagem (13. ed.). São Paulo, SP: Hucitec.

Brait, B. (2005). Bakhtin e a natureza constitutivamente dialógica da linguagem. In B. Brait (Ed.), Bakhtin: Dialogismo e construção de sentido (pp. 87-98). Campinas, SP: Editora da Universidade Estadual de Campinas.

Bruner, J. (1991). The narrative construction of reality. Critical Inquiry, 18, 1-21.

Colaço, V. de F. R. (2004). Processos Interacionais e a construção de conhecimento e subjetividade de crianças. Psicologia: Reflexão e Crítica, 17, 333-340.

Flick, U. (2007). Uma introdução à pesquisa qualitativa (2. ed.). Rio de Janeiro, RJ: Lamparina.

Greig, P. (2007). A criança e seu desenho: O nascimento da arte e da escrita. Porto Alegre, RS: Artmed.

Hermans, H. J. M. (1996). Voicing the self: From information processing to dialogical interchange. Psychological Bulletin, 19, 31-50.

Hermans, H. J. M. (2001). The dialogical self: Toward a theory of personal and cultural positioning. Culture \& Psychology, 7, 243-281.

Marková, I. (2006). Dialogicidade e representações sociais: As dinâmicas da mente. Petrópolis, RJ: Vozes.

Sacks, H., Schegloff, E. A., \& Jefferson, G. (1974). A simplest systematic for the organization of turn-taking for conversation. Language in Society, 50, 696-735.

Silva, S. M. C. (1998). Condições sociais da constituição do desenho infantil. Psicologia USP, 9,4-16.

Vigotski, L. S. (2001). A construção do pensamento e da linguagem. São Paulo, SP: Martins Fontes.

Vigostki, L. S. (2005). A formação social da mente (7. ed.). São Paulo, SP: Martins Fontes.

Vigotski, L. S., Luria, A. R., \& Leontiev, A. N. (1998). Linguagem, desenvolvimento e aprendizagem. São Paulo, SP: Ícone. 